\title{
Em memória de Ana Margarida Miguel Ferreira Nogueira
}

Todos que conheceram Ana Margarida, em sua forma de ser tão peculiar, sabem o quanto sua presença era marcante o suficiente para imediatamente preencher o espaço em que ela se encontrasse, causando forte impressão nas pessoas. Seu tom vibrante definitivamente não passava despercebido. De espírito indômito e pensamento livre, para ela não havia meios-termos ou meias-palavras na sua forma de ser ou agir, mesmo que isso lhe custasse alto preço em muitos aspectos de sua vida pessoal e/ou profissional. Com ela não havia pacto com a mediocridade, conformismo, incompetência ou inércia.

Muitos adjetivos de uma lista enorme talvez não bastem para caracterizá-la: empreendedora, impulsiva, voluntariosa, perfeccionista, ética, entusiasta, assídua, extremada, guia, polivalente, desbravadora, espirituosa, tempestuosa, pontual, crítica, dedicada, guerreira, corajosa, brilhante, rigorosa, competente, e, sobretudo, leal aos compromissos de trabalho e à instituição que representava com muito orgulho. Presença forte e marcante em todas as áreas de atuação de nosso Departamento de Anatomia Patológica e Medicina Legal da Universidade Federal de Minas Gerais (UFMG).

Ana Margarida nasceu em Portugal, em 1955, e mudou-se para o Brasil em 1973 com sua família, vinda de Lisboa onde já havia iniciado o curso médico. Assim, teve de recomeçar o curso na Faculdade de Medicina de Barbacena, que a aceitou naquele momento político difícil para Portugal (Estado Novo), motivo da mudança para o Brasil. Ela adotou nosso país e se naturalizou brasileira.

Durante o curso médico em Barbacena, Ana Margarida conheceu o professor Luigi Bogliolo, que havia se transferido para lá após sua aposentadoria compulsória na UFMG, aos 70 anos. Ao perceber o potencial de trabalho e entusiasmo da aluna com a patologia, o prof. Bogliolo aceitou-a como monitora e ela o acompanhou durante o restante do curso médico. Posteriormente mudou-se para Belo Horizonte, a fim de fazer a residência médica em Anatomia Patológica no Hospital das Clínicas da UFMG (1980-1983). Após a residência, cursou mestrado (concluído em 1988) e doutorado (concluído em 1996) no Programa de Pós-Graduação em Patologia da UFMG.

Ana dedicou-se integralmente à carreira acadêmica e à pesquisa, ingressando como professora de Anatomia Patológica no Departamento de Anatomia Patológica e Medicina Legal da Faculdade de Medicina da UFMG (APM/FM/UFMG), em 1987, no qual trabalhou com dedicação exclusiva, atuando nas áreas de ensino, pesquisa e extensão.

Ana Margarida fez pós-doutorado no Instituto de Patologia e Imunologia Molecular da Universidade do Porto (IPATIMUP), em Portugal (1997-1998) e, ao retornar ao Brasil, integrou e liderou o grupo de pesquisa em patologia digestiva do Conselho Nacional de Desenvolvimento Científico e Tecnológico (CNPq), juntamente com colegas do APM e de outros departamentos da FM/UFMG. Também coordenou diversos projetos de pesquisa do CNPq, da Fundação de Amparo à Pesquisa do Estado de Minas Gerais (FAPEMIG) e convênios de cooperação internacional da Coordenação de Aperfeiçoamento de Pessoal de Nível Superior (CAPES) em intercâmbio com o IPATIMUP. Com a fundação do Instituto Alfa de Gastroenterologia do Hospital das Clínicas da UFMG, passou a integrar e depois a coordenar o Serviço de Anatomia Patológica desse instituto, colaborando ativamente com os serviços de Gastroenterologia e Cirurgia.

Ana foi professora dos cursos de graduação e pós-graduação em patologia, tendo sido coordenadora de ambos. Além disso, foi coordenadora da residência médica em patologia e preceptora da residência médica, com extrema dedicação aos residentes. Fez preceptoria especial de patologia digestiva e de medula óssea, cujos serviços especiais ela estruturou e manteve nesses 25 anos, com a colaboração de outros colegas.

Sua carreira científica é sólida. Foi pesquisadora do CNPq e publicou 83 trabalhos completos em periódicos (52 em periódicos internacionais), apresentou 126 trabalhos em congressos científicos, com vários prêmios em congressos nacionais e internacionais, e dez capítulos de livros. Orientou 41 bolsistas de iniciação científica, 11 mestrandos, cinco doutorandos e três alunos de aperfeiçoamento e ainda participou como palestrante, coordenadora de atividades e membro da Comissão Cientifica dos Congressos de Patologia da Sociedade Brasileira de Patologia (SBP), incluindo o nosso XXVI Congresso de Bento Gonçalves (2007), no qual auxiliou a comissão científica, avaliou trabalhos, coordenou minissimpósio, bem como participou de atividades de patologia digestiva e colaborou ativamente em trabalhos do Jornal Brasileiro de Patologia e Medicina Laboratorial (JBPML), como autora e analisadora.

Ana Margarida deixa um legado vivo de educação, de formação de pessoas, de grande capacidade de produzir, de orientar alunos, residentes e pós-graduandos, de ser séria e competente e de amar a patologia. Como amigos e colegas, manifestamos nosso profundo respeito e admiração pela maneira como se dedicou inteiramente a tudo que fazia com seriedade e dedicação.

Não esqueceremos jamais que seus últimos instantes de vida foram ao lado de alguns de nós, seus colegas, em reunião de trabalho no Hospital das Clínicas da UFMG, defendendo a qualidade de nosso trabalho, naquela tarde do dia 26 de novembro de 2007 , às $16: 30 \mathrm{~h}$. 